Supplement of Geosci. Model Dev., 13, 2475-2486, 2020

https://doi.org/10.5194/gmd-13-2475-2020-supplement

(C) Author(s) 2020. This work is distributed under

the Creative Commons Attribution 4.0 License.

(c) (1)

Supplement of

\title{
An adaptive method for speeding up the numerical integration of chemical mechanisms in atmospheric chemistry models: application to GEOS-Chem version 12.0.0
}

Lu Shen et al.

Correspondence to: Lu Shen (1shen@fas.harvard.edu)

The copyright of individual parts of the supplement might differ from the CC BY 4.0 License. 
1 Table S1. Partitioning of GEOS-Chem chemical species ${ }^{\mathrm{a}}$ into $N=12$ blocks. Results are from

2 running the algorithm with different initializations.

Optimization $1^{\mathrm{b}}$

\begin{tabular}{|c|l|}
\hline 1 & $\begin{array}{l}\text { CH2I2 CH2ICl CH2IBr SOAMG CH3CCl3 CH3I H1301 H2402 CC14 CFC11 CFC12 CFC113 } \\
\text { CFC115 H1211 OCS CHBr3 CHCl3 HCFC123 HCFC141b HCFC142b HCFC22 CH3Br NPMN } \\
\text { MAOPO2 NMAO3 }\end{array}$ \\
\hline 2 & $\begin{array}{l}\text { ISN1OA ISN1OG LISOPNO3 LVOCOA LVOC LXRO2H LXRO2N PYAC DHDN DHDC PMNN } \\
\text { CFC114 IEPOXD XRO2 CH2Br2 XYLE PRPN DHPCARP IAP MOBA DHMOB ISNP MAOP MRP } \\
\text { CHPD ETHLN ISNOHOO MOBAOO DIBOO LIMO ISNOOB MACRNO2 ISOPNB MVKOO GAOO } \\
\text { OLNN LIMO2 ISOPNBO2 ISOPND ISN1 INO2 }\end{array}$ \\
\hline 3 & $\begin{array}{l}\text { LISOPOH LTRO2N SOAGX SOAME MONITA IEPOXB PIP HPALD VRP HPC52O2 HONIT RIPB } \\
\text { RIPA MTPA MTPO INPN ROH MONITS MVKN CH2OO PROPNN OLND PIO2 HC5OO HC5 } \\
\text { RIO2 MRO2 }\end{array}$ \\
\hline 4 & $\begin{array}{l}\text { MSA MAP ETP CH3Cl SO4 ALK4 R4P C3H8 ATOOH C2H6 B3O2 ATO2 KO2 MGLY ACET R4O2 } \\
\text { RCHO MEK }\end{array}$ \\
\hline 5 & $\begin{array}{l}\text { INDIOL LTRO2H SOAIE IMAE TOLU TRO2 IEPOXA IONITA IMAO3 HC187 IPMN IEPOXOO } \\
\text { PO2 R4N1 ISOP HCOOH VRO2 R4N2 PRPE MACR MVK }\end{array}$ \\
\hline 6 & SO4H1 PPN DMS PAN RCO3 ACTA ETO2 ALD2 MCO3 SO2 \\
\hline 7 & $\begin{array}{l}\text { LBRO2H LBRO2N SO4H2 BENZ BRO2 CH2C12 RA3P RB3P RP PP EOH GLYX A3O2 GLYC } \\
\text { HAC }\end{array}$ \\
\hline 8 & CO2 N2O N HNO4 HNO2 MP H CH4 H2O2 CO O1D O \\
\hline 9 & MPN N2O5 HNO3 CH2O MO2 O3 NO HO2 NO3 NO2 H2O OH \\
\hline 10 & ClOO BrCl Br2 BrNO3 HOBr HOCl ClNO3 Cl HBr ClO HCl \\
\hline 11 & I2O2 BrNO2 Cl2O2 IONO OIO OClO HOI IONO2 Cl2 I IO BrO Br \\
\hline 12 & AERI ISALA ISALC I2O4 I2O3 IBr INO HI ICl CINO2 BrSALC BrSALA I2 \\
\hline
\end{tabular}

Optimization $2^{\mathrm{c}}$

\begin{tabular}{|c|l|}
\hline 1 & $\begin{array}{l}\text { LISOPOH DHDC MONITA CHBr3 CHCl3 HCFC22 PRPN PIP HPALD HONIT RIPB RIPA MTPA MTPO } \\
\text { LIMO INPN ROH MONITS ISOPNB CH3CHOO MVKN PRN1 MGLOO MONITU CH2OO PROPNN } \\
\text { OLND OLNN PIO2 HC5OO ISOPND HC5 RIO2 MRO2 }\end{array}$ \\
\hline 2 & SO4H1 PPN MAP C2H6 ATO2 RCO3 ACTA ACET ETO2 ALD2 \\
\hline 3 & MSA ETP RB3P CH3Cl SO4 ALK4 R4P C3H8 ATOOH B3O2 KO2 MGLY R4O2 RCHO MEK \\
\hline 4 & INDIOL N2O IONITA N R4N2 PRPE \\
\hline 5 & $\begin{array}{l}\text { CH2IBr ISN1OA ISN1OG LVOCOA LVOC PYAC SOAMG DHDN CH3CCl3 H1301 H2402 PMNN CCl4 } \\
\text { CFC11 CFC12 CFC113 CFC114 CFC115 H1211 IEPOXD CH2Br2 HCFC123 HCFC141b HCFC142b } \\
\text { CH3Br DHPCARP IAP VRP HPC52O2 MOBA DHMOB ISNP MAOP MRP RIPD ETHLN ISNOHOO } \\
\text { NPMN MOBAOO DIBOO ISNOOB MACRNO2 MVKOO GAOO MGLYOO MAN2 ISNOOA ISOPNDO2 } \\
\text { MACROO MACRN MAOPO2 LIMO2 ISOPNBO2 NMAO3 }\end{array}$ \\
\hline 6 & $\begin{array}{l}\text { LISOPNO3 LTRO2H LTRO2N LXRO2H LXRO2N SOAGX SOAIE SOAME IMAE TOLU TRO2 IEPOXA } \\
\text { IEPOXB XRO2 IMAO3 XYLE HC187 IPMN IEPOXOO GLYX R4N1 ISOP HCOOH GLYC VRO2 ISN1 } \\
\text { INO2 MACR MVK }\end{array}$ \\
\hline 7 & $\begin{array}{l}\text { CH2I2 CH2IC1 LBRO2H LBRO2N SO4H2 BENZ CH3I BRO2 OCS CH2C12 RA3P RP PP EOH A3O2 PO2 } \\
\text { HAC }\end{array}$ \\
\hline 8 & CO2 DMS HNO4 HNO2 PAN MP H CH4 H2O2 CH2O MCO3 SO2 CO O1D O \\
\hline 9 & MPN N2O5 HNO3 MO2 O3 NO HO2 NO3 NO2 H2O OH \\
\hline 10 & AERI ISALA ISALC I2O4 I2O3 IBr INO HI CINO2 BrSALC BrSALA I2 \\
\hline
\end{tabular}


11 ClOO BrCl Br2 BrNO3 HOBr HOCl ClNO3 $\mathrm{Cl} \mathrm{HBr} \mathrm{ClO} \mathrm{HCl}$ $12 \mathrm{I} 2 \mathrm{O} 2 \mathrm{BrNO} 2 \mathrm{ICl} \mathrm{Cl} 2 \mathrm{O} 2$ IONO OIO OClO HOI IONO2 Cl2 I IO BrO Br

1 The full GEOS-Chem mechanism has 228 species. The full names of these acronyms can be

2 found at http://wiki.seas.harvard.edu/geos-chem/index.php/Species in GEOS-Chem. The blocks

3 defined here are combined in the algorithm to generate $M=20$ different chemical regimes as

4 subsets of the full mechanism.

5 bThe median RRMS error after 12 months is $0.67 \%$ if we use a threshold $\delta$ of 500 molecules $\mathrm{cm}^{-3}$ $6 \quad \mathrm{~s}^{-1}$ to define the fast and slow species.

$7 \quad{ }^{\mathrm{c}}$ The median RRMS error after 12 months is $0.63 \%$ if we use a threshold $\delta$ of 500 molecules $\mathrm{cm}^{-3}$ $8 \mathrm{~S}^{-1}$ to define the fast and slow species. 
Fast blocks for anthropogenic VOCs (block 4)

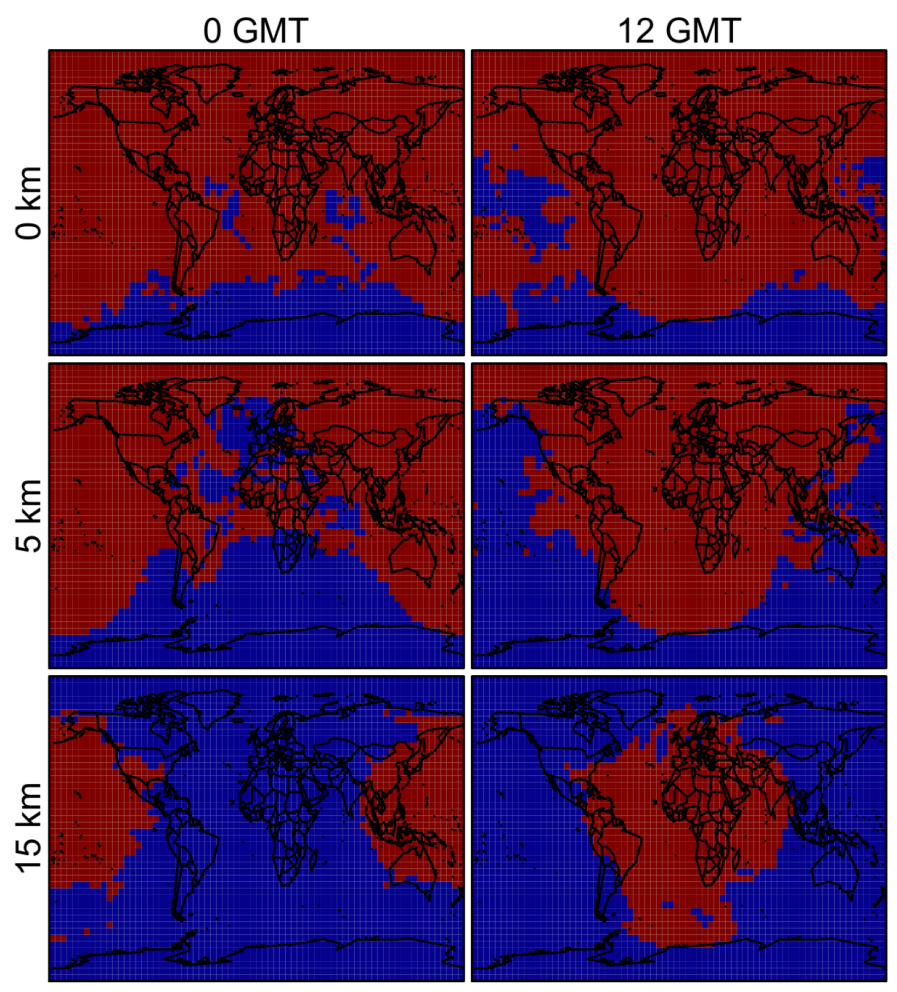

1 Figure S1. Locations of block 4 that needs to be solved as fast (red) or slow (blue). Block 4 3 mainly contains anthropogenic alkanes, alkenes and acetone. Results are shown on August 12013 4 at 0 and 12 GMT using a threshold $\delta$ of 100 molecules $\mathrm{cm}^{-3} \mathrm{~s}^{-1}$ to define the fast and slow 5 species. 
Fast blocks for anthropogenic VOCs (block 5)

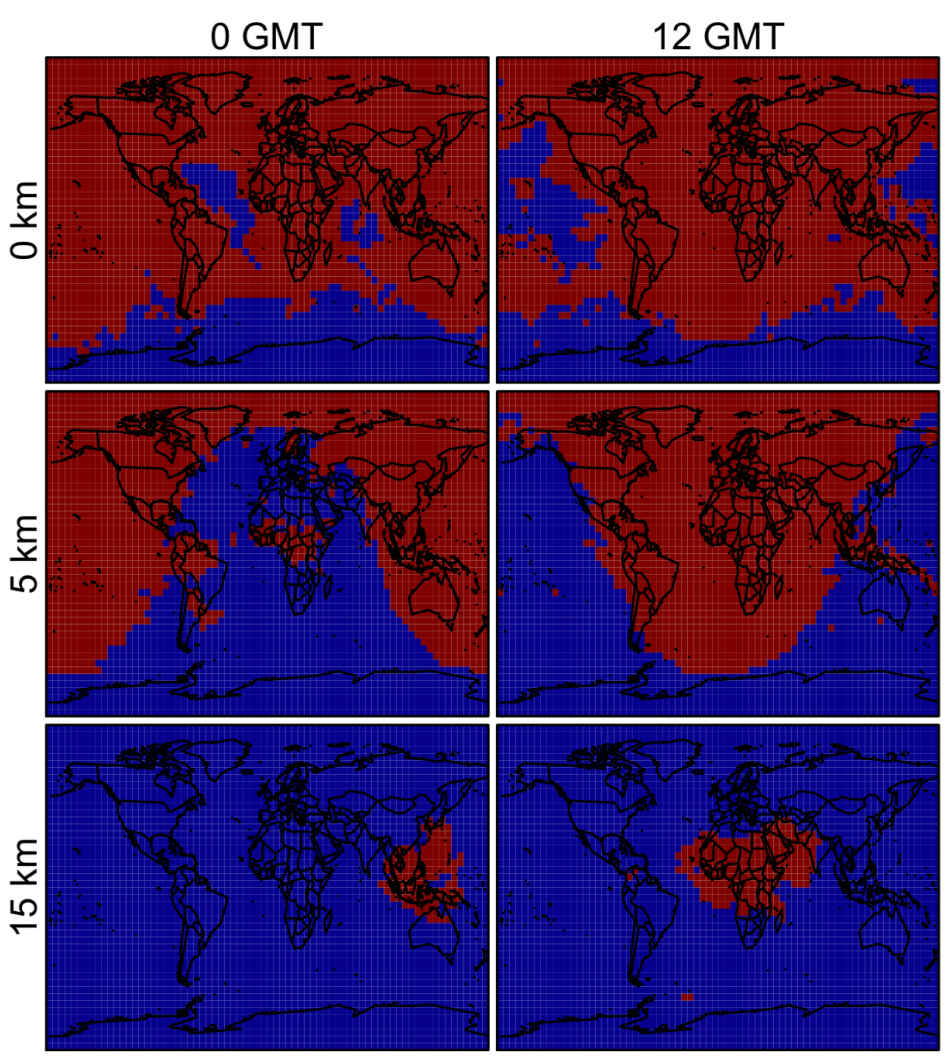

Figure S2. Same as Figure S1 but for Block 5, which includes higher alkanes and methyl ethyl ketone from anthropogenic sources. The fast species is denoted as red and the slow one denoted as blue. 


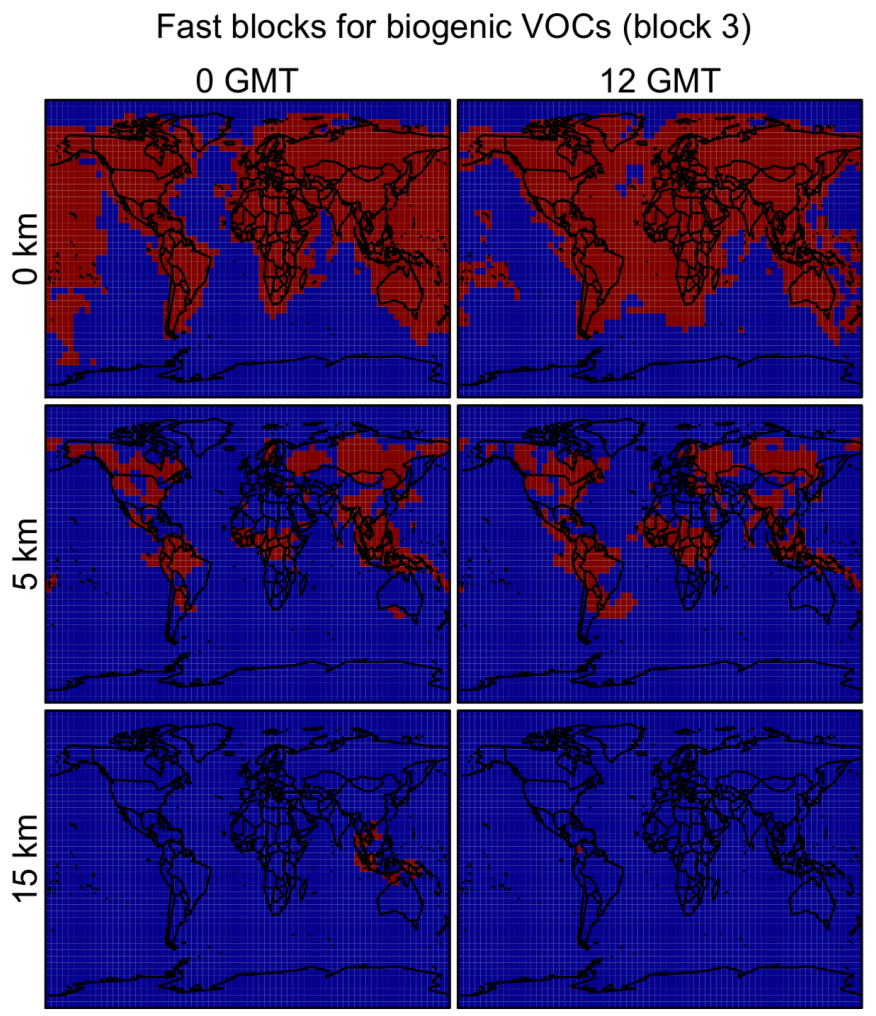

1

Figure S3. Same as Figure S1 but for Block 3, which mainly contains isoprene and terpenes. The 3 fast species is denoted as red and the slow one denoted as blue. 
Fast blocks for biogenic VOCs (block 6)

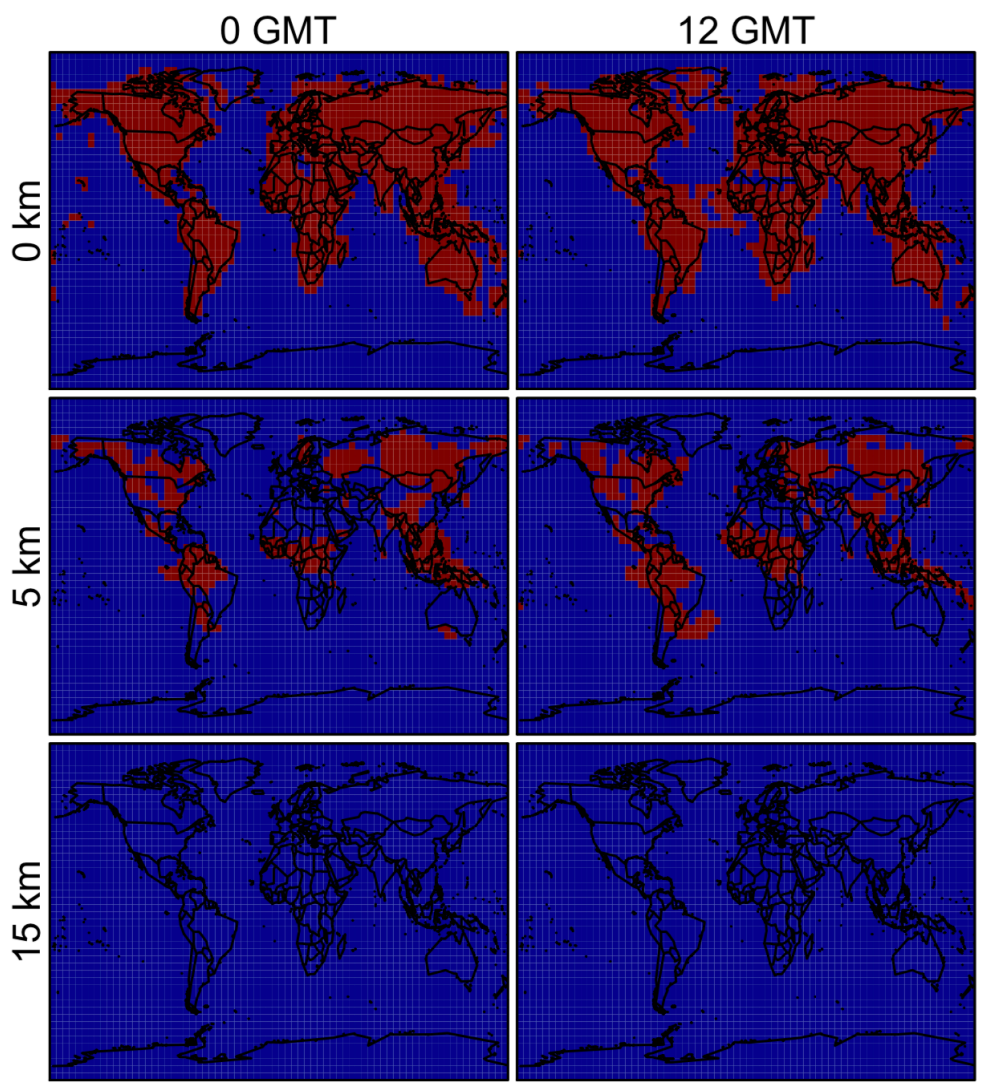

Figure S4. Same as Figure S1 but for Block 6, which mainly contains isoprene products and a few halocarbons. The fast species is denoted as red and the slow one denoted as blue.

4

5 


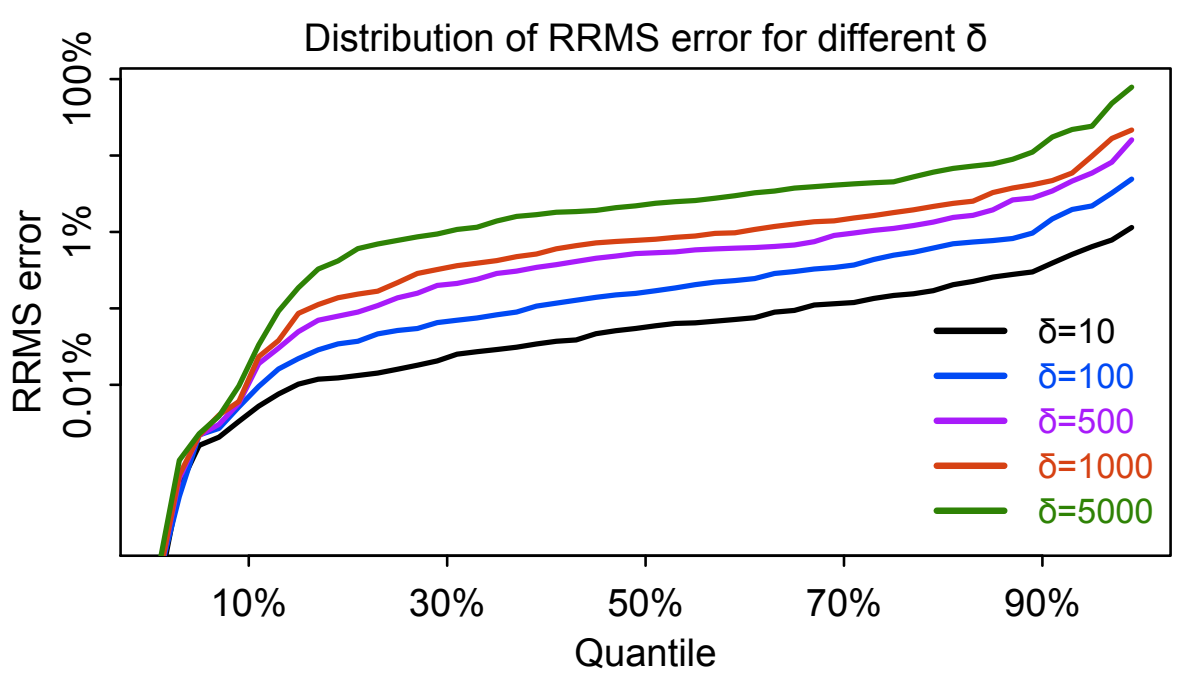

2 5

Figure S5. Distribution of RRMS error for different thresholds $\delta(N=12$ and $M=20)$. The y axis is on the logarithmic scale.

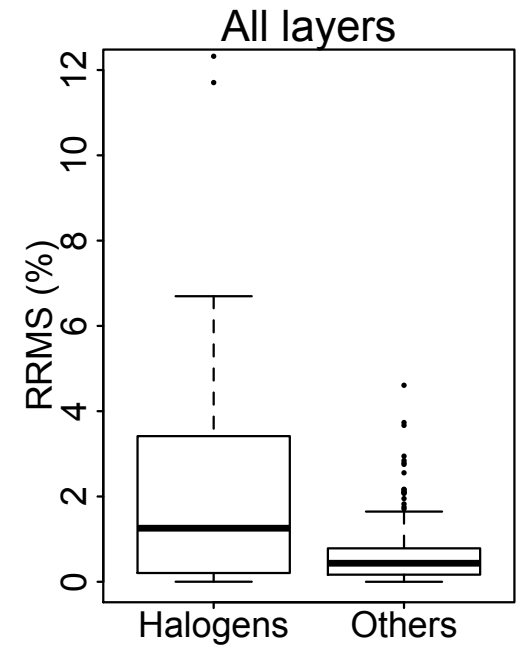

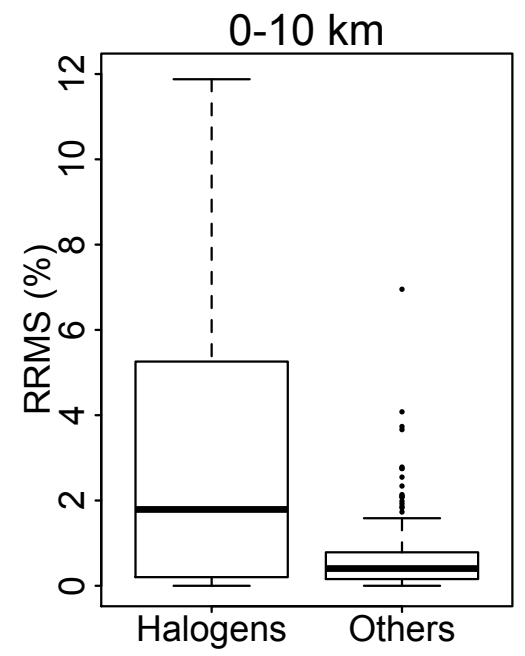

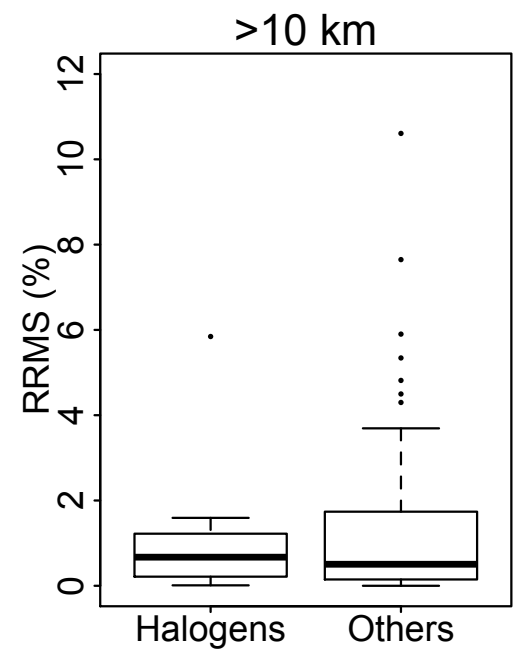

6

Figure S6. The RRMS error of halogen and non-halogen species for (a) all layers, (b) 0-10 km and (c) above $10 \mathrm{~km}$. Results are shown for the daily-average concentrations of all species on the last day of the 2-year simulations, using 20 chemistry regimes and a threshold $\delta$ of 500 molecules $\mathrm{cm}^{-3} \mathrm{~s}^{-1}$. 
Relative error in the adpative mechanism reduction method

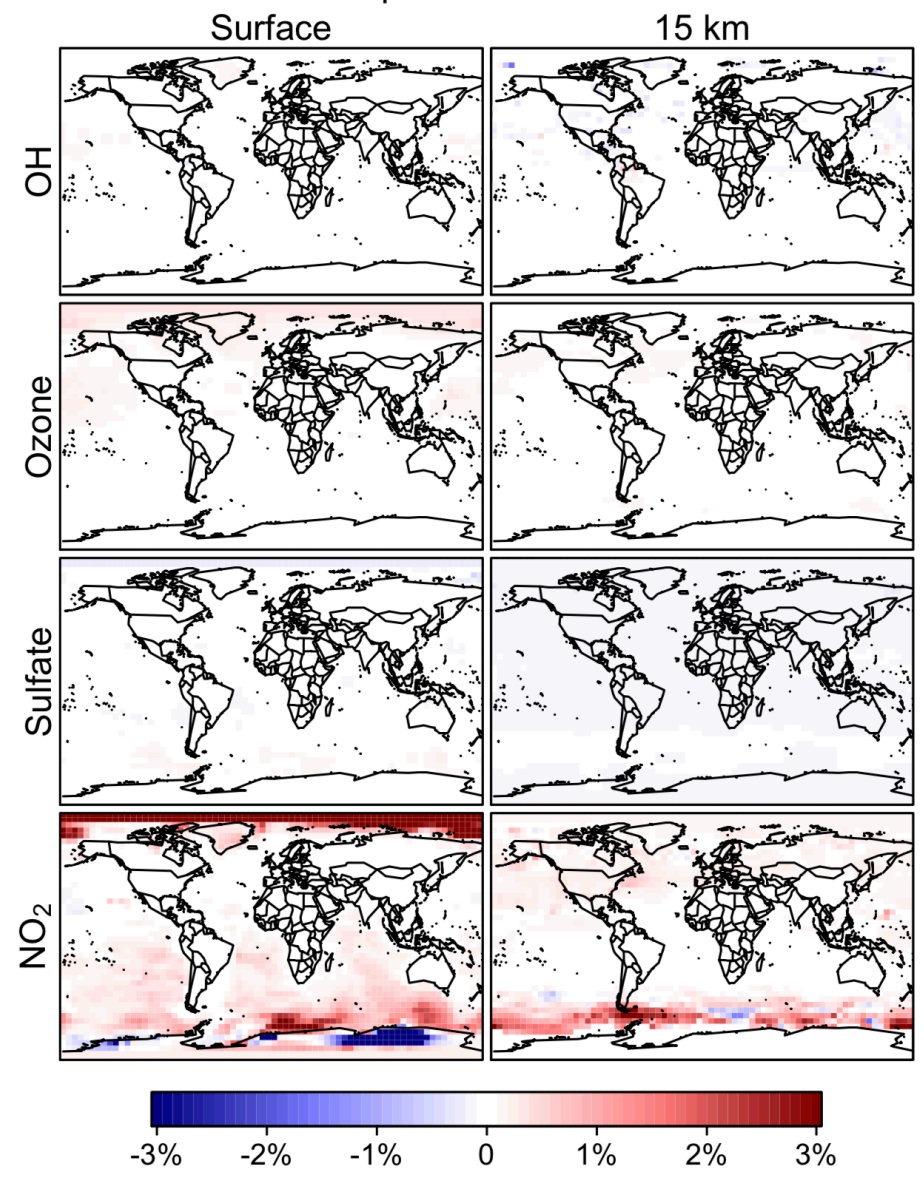

Figure S7. Same as Figure 6 but using a rate threshold $\delta=100$ molecules $\mathrm{cm}^{-3} \mathrm{~s}^{-1}$ to partition the 3 species between fast and slow. 


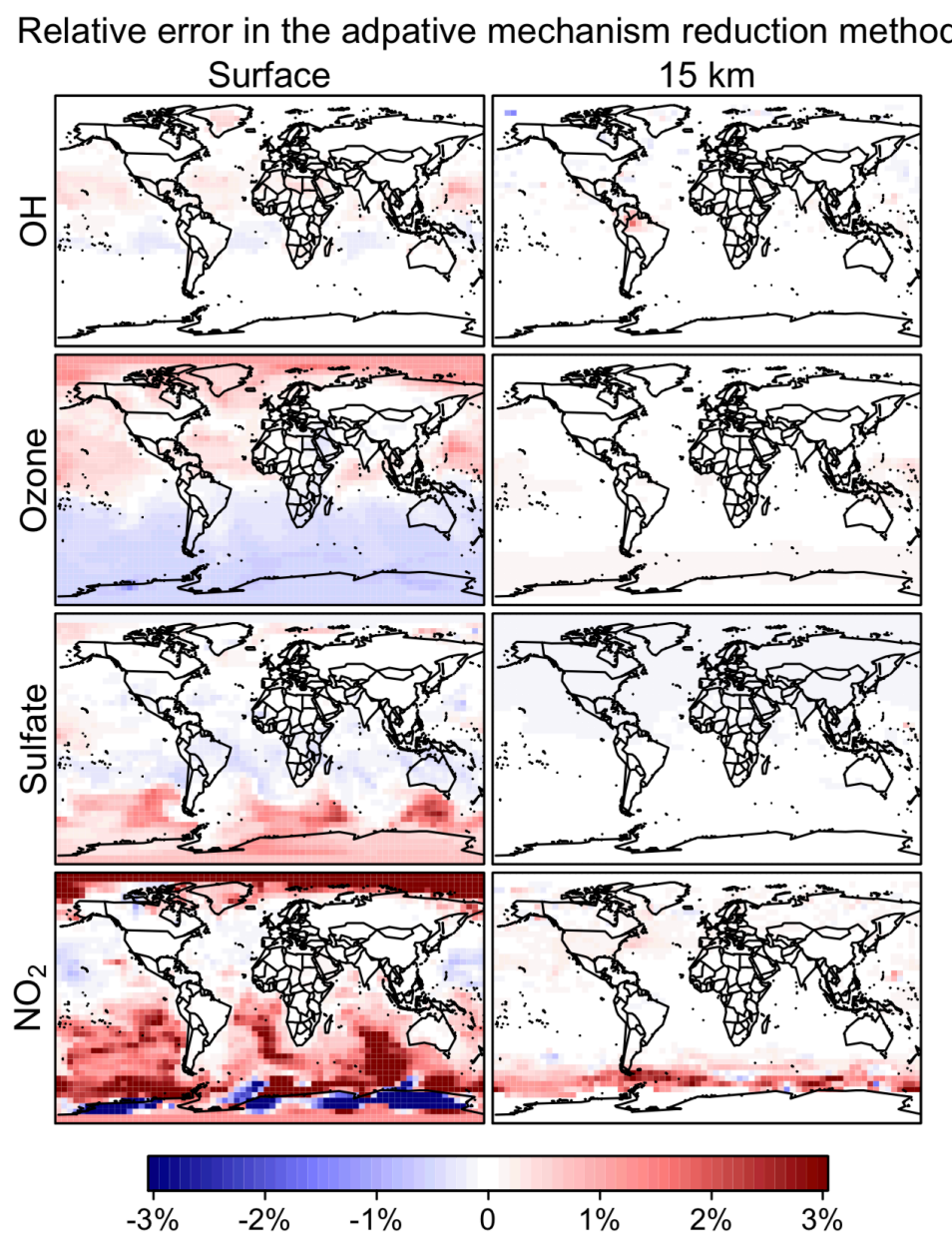
2 3 4

Figure S8. Same as Figure 7 but using a rate threshold $\delta=1,000$ molecules $\mathrm{cm}^{-3} \mathrm{~s}^{-1}$ to partition the species between fast and slow. 